Original Research Paper

\title{
Hands-On Fire Extinguisher Training Apparatuses: Expert Evaluations of Two Propane Fire Simulators and Air- Pressurized Water Extinguishers
}

\author{
Awwad Dababneh, Abdul Jaleel Hamad Majeed and Rami H. Fouad \\ Department of Industrial Engineering, University of Jordan, Amman, 11942, Jordan
}

Article history

Received: 31-05-2015

Revised: 11-07-2017

Accepted: 25-07-2017

Corresponding Author: Awwad Dababneh

Department of Industrial Engineering, University of Jordan, Amman, 11942, Jordan Email: dababneh@ju.edu.jo

\begin{abstract}
Twenty-two expert firefighting professionals were used in evaluating four methods for fire extinguisher hands-on training. Two different fire simulators were put into service along with two conditions for the fighting distance; keeping a distance of $2.44 \mathrm{~m}$ (8ft.) away from the base of the fire and having no restriction on getting closer to the fire. The fire simulators both utilized burned propane gas and modified air pressurized water extinguishers. Demographics data were gathered at the beginning of the study and participants completed a study form after each study conditions and at the end of the study. The participants are required to provide comments and suggestions as well. Results showed that participants preferred and recommended one simulator over the other for better simulating a real situation. Moreover, the participants reported that keeping a $2.44 \mathrm{~m}$ (8ft.) fighting distance is not realistic and maybe questionable as it is counter to proper use of extinguishers. Participants suggests adding smoke, sound and light effects to better simulate a real situation and improve training.
\end{abstract}

Keywords: Hands-on Training, Fire Extinguisher, Fire Simulator, AirPressurized Water Extinguisher, Experts Evaluation

\section{Introduction}

Occupational Health and Safety Administration (OSHA) regulations in the United States; require "handson" fire extinguisher training for all workplace employees who have been designated to use fire extinguishers. These standards also require that an employer provide an educational program (which may or may not include hands-on training) to familiarize all employees with the general principles of fire extinguisher use (OSHA, 2013) (see OSHA 1910.157 (g) (Blackburn et al., 2010; Darois et al., 2007). Notably, though, most firefighters and Professional Safety Associations (e.g., the National Safety Council (NSC) and National Fire Protection Association (NFPA)) view hands-on training as the only viable option that can ensure all employees can use extinguishers safely and effectively.

A study by Poole (2012) at Eastern Kentucky University investigated the effects of hands-on fire extinguisher training on the ability of ordinary people to put out small fires. The results demonstrated that subjects were able to operate a fire extinguisher without prior training, although their conclusion might have been biased somewhat by the subject demographics: Subjects were students recruited voluntarily from the campuses of Worcester Polytechnic Institute and Eastern Kentucky University, both of which have firefighting/safety educational programs and which raises a plausible concern that the subjects may have had higher than average interest and knowledge regarding portable extinguishers than the general public. Regardless, the study also reported that participants showed improved performance and confidence in the effective operation of a fire extinguisher and that the improvement was attributable to the hands-on training.

The traditional method for hands-on extinguisher training includes the use of actual extinguishers and a fire pan. Typically, the fire pan is a metallic flat pan about $5-10 \mathrm{~cm}$ (2-4 inches) deep. The pan allows trainers to start and contain a controlled fire for training. The pan is usually half filled with water and a small amount of a gasoline and diesel fuel mixture is poured over the water in the pan. The water helps keep the overall temperature of the fuel low and thus slows evaporation. The fuel 
mixture is lighter than water and floats on top. The resulting fire is a class $\mathrm{B}$ fire for which foam, powder, or $\mathrm{CO}_{2}$ fire extinguishers may be used to put it out. However, because of the mess and the difficulty in quickly re-igniting a fire for subsequent training sessions, foam and powder extinguishers are rarely used. On the other hand, $\mathrm{CO}_{2}$ extinguishers, leave no residue and allow for quickly re-igniting the fire and are thus the preferred choice to use with the fire pan method. The major challenges for using the traditional fire pan method include cost and the negative impact on the environment. Although the pan itself is not expensive to construct, re-charging the fire extinguishers can be expensive and time-consuming. These two factors are often limit the amount of practice a trainee receives. Further, the foam, powder and $\mathrm{CO}_{2}$ fire extinguishing agents have negative impacts on the environment, ranging from being "dirty and messy" to contributing to global warming by releasing $\mathrm{CO}_{2}$ into the air.

Driven by the increased demand for hands-on training and by the shortcomings of the traditional fire pan method, several extinguisher training apparatus designs have been developed and commercialized in the past decade. Review of patents revealed clear design trends for protecting the environment, simplifying operations of apparatuses and reducing cost of training. Design solutions included real and virtual simulation of fire. Real fire simulators used propane fuel to produce a clean fire (Hoglund, 2005; Darois et al., 2007; Joynt et al., 1995; Williamson and Orotelli, 2010) while virtual simulators used equipment similar to those used with electronic games (Deshoux et al., 2000; Moore, 2004; Blackburn et al., 2010). Also, air-pressurized water extinguisher is used in training for their low cost of researching and low environmental impact. Unfortunately, little viable research has been published investigating the effectiveness of these training methods.

The combination of the propane fire simulator and the air pressurized water extinguisher provides means for safe, clean and inexpensive training. However, propane gas fire does not normally extinguish with water. The two simulators subject of study use two different design-concepts that make air-pressurized water extinguisher capable of putting out the simulated fire.

The first simulator is commercially available in the United States and hereafter is referred to as Fire Simulator Number One (FS1) as shown in Fig. 1. It uses a controlled propane-fueled fire to simulate an incipient stage fire. The FS1 is designed with sensors that detect the trainee's aiming and sweeping motions; the system automatically shuts off the fuel via a solenoid valve if the proper motions are detected. Some concerns, however, regarding the effectiveness of this and similar training devices can be raised.

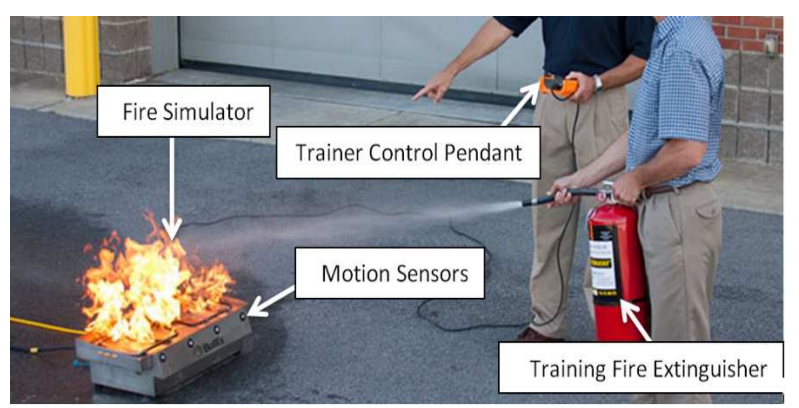

Fig. 1. Components of the FS1

One concern is that, in order for the FS1 unit to function properly, trainees using this simulator are instructed to stay at least $2.44 \mathrm{~m}$ (8ft.) away from the fire (Bullex ITS, 2012). This distance requirement appears to stem from the design of the unit: The author's experiences has been that at shorter distances the sensors do not function correctly and that the pilot light might get wet and fail to operate. Moreover, this distance requirement is not consistent with National Fire Protection Association (NFPA) recommendations for extinguisher use (HAI, 2010, Quincy, 2007). Rather, the NFPA recommends that users start discharging the extinguisher from a safe distance (e.g., $2.44 \mathrm{~m}$. or $8 \mathrm{ft}$.) and to move closer as the fire subsides to maintain effectiveness. In addition, the effective fighting distance depends on the type of fire extinguisher. For example, a $\mathrm{CO}_{2}$ extinguisher loses effectiveness when the discharge nozzle is more than

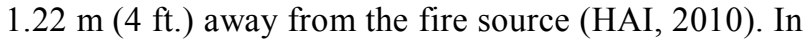

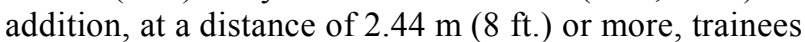
are less likely to feel the heat of the fire and may develop a false sense of confidence in their ability to deal with fire in a real situation. Therefore, keeping a distance of $2.44 \mathrm{~m}$ (8ft.) away from the fire when using the FS1 training apparatus is counter to the NFPA guidelines, does not accurately represent the true fighting range for regular extinguisher and may not realistically replicate the experience of fighting an actual fire. Moreover, the FS1 and similar equipment are rather expensive, with a complete simulator system costing more than few thousand dollars (US), depending on number of training extinguishers included, system and accessories.

Nonetheless, the clean propane fire and easily rechargeable water extinguishers lend themselves well to hands-on training due to their very low environmental impact and low operational costs. Building on these positive design aspects, an alternative fire simulator was developed to maintain the benefits of using a propanefueled fire and air-pressurized water extinguishers while more realistically simulating an actual fire. The new design is called the "Honeycomb" fire simulator. 


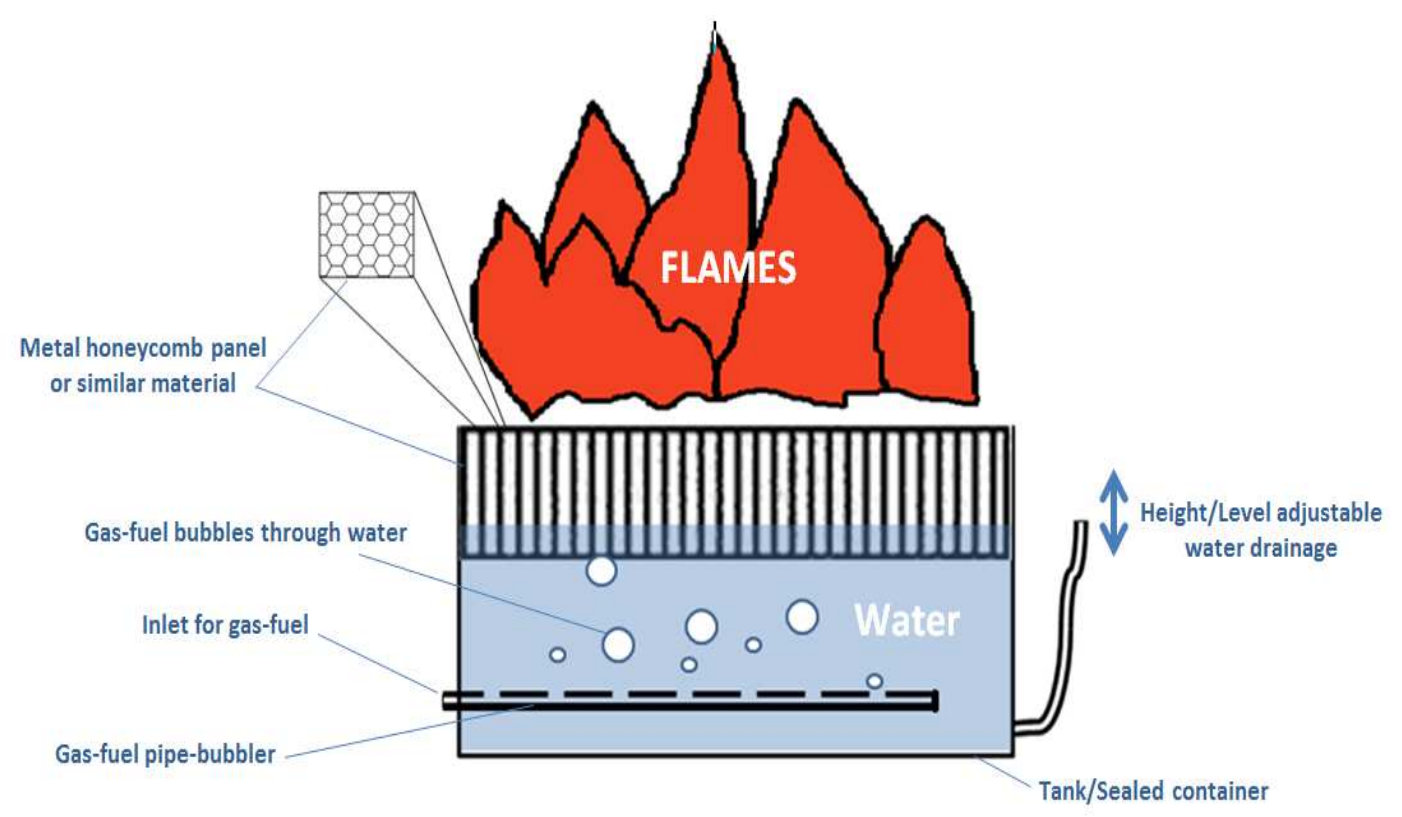

Fig. 2. The "Honeycomb" fire simulator

Figure 2 illustrates all parts and construction of the honeycomb fire simulator. The largest part of the simulator is a leak-proof tank or container. The top side of the tank is open while the cross section of the tank may be of any shape: Circular, oval, rectangular, etc. The tank is partially filled with water and a height adjustable drainage tube controls and keeps the water level unchanged. Propane gas enters the simulator at the bottom of the tank through a dedicated pipe. The pipe is perforated to allow the gas to bubble up through the water. A metal honeycomb panel is installed at the top of the tank, completely covering the open side of the tank. The honeycomb panel is constructed of small tubes joined along their sides to create a 2 inch thick open grid, entirely comprised of $6 \times 6 \mathrm{~mm}(0.25 \times 0.25 \mathrm{inch})$ holes. As the bubbled gas come in contact with the bottom side of honeycomb panel, the gas is divided into many small bubbles that each escape from one of the openings in the panel. Once the simulator is lit, the flames flicker vertically above and across the grid, creating a blanket of flames. When using the air-pressurized water extinguisher with the honeycomb simulator, flames are extinguished by the combined actions of cooling the fire and blowing the flames off the top of the honeycomb panel. This approach creates a flame front that behaves like the flames in class B fires. As a result, the trainee has to use sweeping motions and "chase" the flame front with the extinguishing stream in order to put it out. The honeycomb grid is kept partially submersed in the water for cooling. Also, the difficulty in extinguishing the flames is controlled by adjusting the level of the water covering the panel; as the level of water rises in the tank, the base of the flames rises with it. As the flames bases become more exposed to the extinguishing stream, it become easier to blow off and get extinguished.

The objective of this study was gain experts' insight, by having a group of professional fire fighters and extinguisher trainers evaluate and compare the FS1 with the Honeycomb simulator.

\section{Materials and Methods}

\section{Participants}

Twenty-two experts participated in this study: Fifteen firefighters and seven professional fire extinguisher trainers. Sixteen participants had conducted fire extinguisher training; of these sixteen, thirteen had trained 100 or more people, two had trained between 30 and 100 people and one had trained fewer than 30 .

All participants reported they were experts: 14 agreed and 8 strongly agreed with the statement "I am an expert in the use of fire extinguishers." Only one participant had not used a fire extinguisher in an actual fire situation. Thirteen participants had completed a four-year college degree or higher, three had earned a two-year college degree and six had no college degrees. Six participants were female and participants ranged in age from 34 to 54 years of age with an average of 42 Participants were recruited from Duluth, Minnesota and surrounding localities. Participants volunteered and did not receive compensation for their involvement in the study.

\section{Equipment and Setup}

One FS1 system and one Honeycomb fire simulator prototype were used in the study. The FS1 system was 
equipped with an automatic pressure regulator, which enabled flame adjustment using pre-programmed settings for different fire classifications (i.e., A, B, or C); in this study, the flames were set to "2 B". The Honeycomb simulator had a manual pressure regulator, which was manipulated so that the height of the flames was comparable to the flames produced by the FS1. Both simulators had similar burning areas as shown in Fig. 3.

The study was conducted inside an engineering materials castings laboratory equipped with large capacity ventilation system and high temperature fire sprinklers. Participants were instructed to use a special training extinguisher to put out a simulated fire for each and all study conditions. The training extinguisher, usually sold with the FS1 simulator, was a standard air pressurized water extinguisher with slight modifications to the syphon pipe, discharge hose and nozzle. The training extinguisher sprayed a mixture of water and air, but looked and operated like a real extinguisher. Four training extinguishers were used in the study; participant started each study condition with a fully charged extinguisher. Fire extinguishers were recharged during the test session only if the participants wanted to further experiment after completing all study conditions. The study conditions were randomized for each participant by asking him or her to pick one of four small numbered pieces of paper before each of the study conditions.

\section{Study Protocol}

Four study conditions were examined by using the FS1 and the Honeycomb fire simulators (simulator type) in a restricted and an unrestricted condition (free style). The restricted training style required participants to keep a distance of $2.44 \mathrm{~m} \mathrm{(8ft.)} \mathrm{away} \mathrm{from} \mathrm{the} \mathrm{front} \mathrm{edge} \mathrm{of}$ the simulator. In the unrestricted training style, participants started at an eight-foot distance from the simulator but were allowed to move towards the fire as they felt necessary.

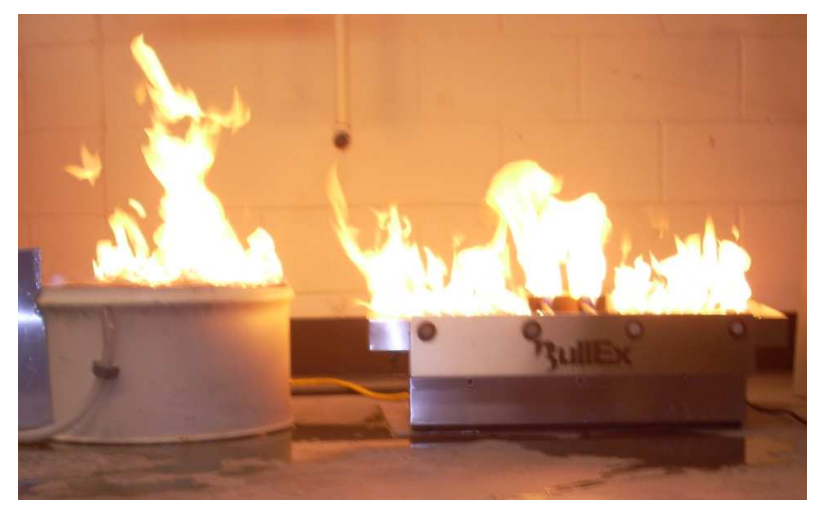

Fig. 3. Flame size for the Honeycomb (right) and the FS1 (left) fire simulators as used in the study (Note: at any given time during the study, only one simulator would be lit)
Each participant was met at the lab entrance and informed of the study objectives and procedure. Participants then were asked to fill a two-part study form. The first part collected demographics and verification information regarding the level of experience each participant had with the use of fire extinguishers; this part was completed before the actual experimentation began. The second part of the study form was administered in stages: After completing each of the four study conditions and at the end of their experiment. After completing each study condition, participants were asked to use a 5-point agreement scale to rate the following statements:

- Putting out this fire simulated putting out a real fire

- This apparatus and method provide means for effective "Fire Extinguisher" training

- Training using this apparatus and method will help trainees put out actual fires safely

- I recommend using this apparatus and method for training

Then, after completing all of the study conditions, participants were asked to rate five different training methods: The four methods associated with each of the study conditions and also the traditional fire pan method. Participants were also requested to indicate the type of fire extinguisher (water, foam, powder, or $\mathrm{CO}_{2}$ ) that the training extinguisher most closely simulated. Participants were also encouraged to provide unstructured feedback through written comments, criticisms and/or suggestions.

A rating items used at the end of each study condition applying 5 likert scale as follows:

- Strongly agree

- 2-Agree

- Neutral

- Disagree

- Strongly disagree

The conclusion of the study rated the five training methods using the following 5 likert scale:

- Preferred

- Acceptable

- Neutral

- Not Recommended

- Objectionable

Basic descriptive statistics were considered for ratings of each of the survey items. Analysis of variance and pairwise comparisons (Tukey's) were used to investigate differences between study conditions. Participants' comments, criticisms and suggestions were categorized and analyzed as well. 


\section{Results}

All twenty-two participants were able to put out the simulated fires for three of the four study conditions. However, only one participant was able to put out the fire in the honeycomb simulator using the restricted training style (a fixed discharge distance of $2.44 \mathrm{~m}(8 \mathrm{ft}$.)).

Figure 4 to 7 presents box-plots of ratings for each of the survey items and across all study conditions. Notably, all four survey items yielded similar results and: Significant differences were found between study conditions $(p=0.000)$. In each case, pairwise comparisons at the $95 \%$ confidence level showed that differences between simulators were significant, but differences between the restricted and unrestricted extinguishing styles were insignificant within each simulator type. Participants consistently rated the honeycomb better than the FS1 system.
The Honeycomb simulator with unrestricted extinguishing distance was rated significantly higher than all other forms of training; for the survey item in which participants were asked to rate the five different training methods, $(\mathrm{P}=0.000$; Fig. 8). Considering the pairwise comparisons at a $95 \%$ confidence level, statistically significant differences were found between the Honeycomb/Unrestricted and all the other methods. In addition, the ratings for the Honeycomb simulator with unrestricted discharging distance were also the most consistent with all ratings either "acceptable" or "preferred." In contrast, the ratings of the traditional fire pan method had the most variability with ratings across the entire ("objectionable" to "preferred"). The average rating for the FS1 simulator with a restricted training style (the manufacturer's recommended method) was "neutral", but it also had the highest number of "objectionable" ratings.

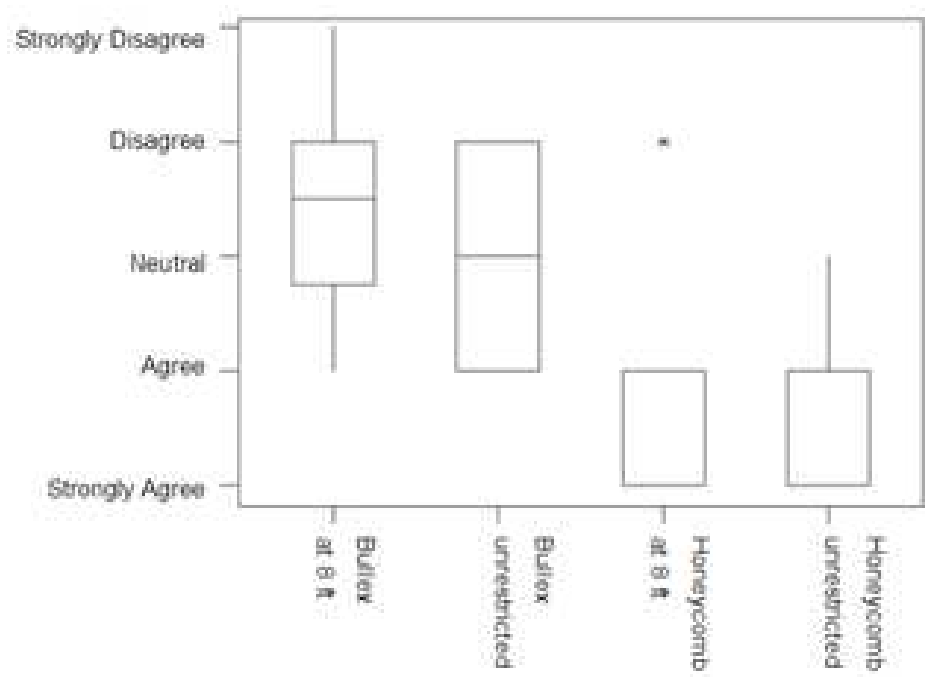

Fig. 4. Participant responses to "Putting out this fire simulated putting out a real fire"

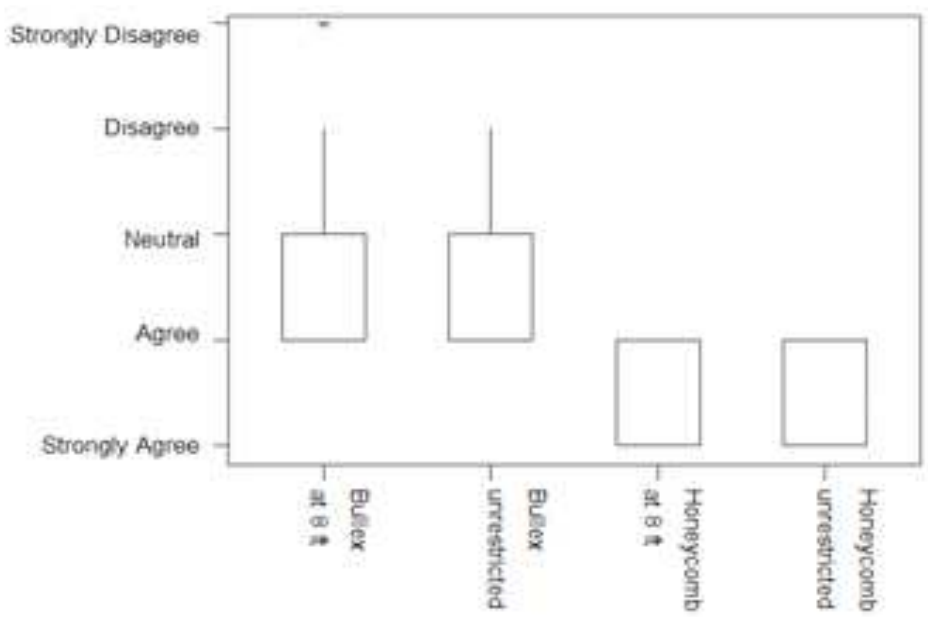

Fig. 5. Participant responses to "This apparatus and method provide means for effective fire extinguisher training" 


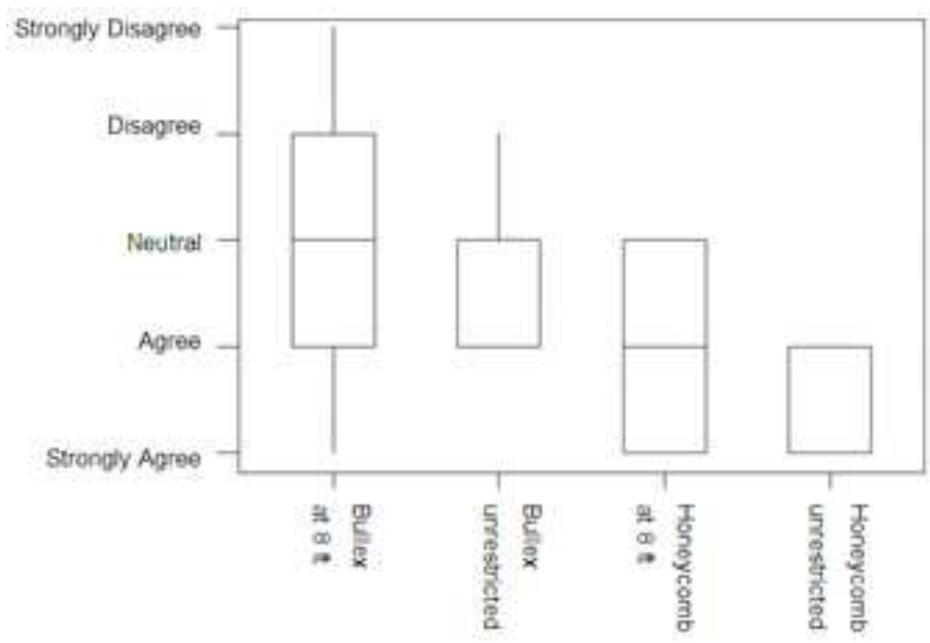

Fig. 6. Participant responses to "Training using this apparatus and method will help trainees put out actual fires safely"

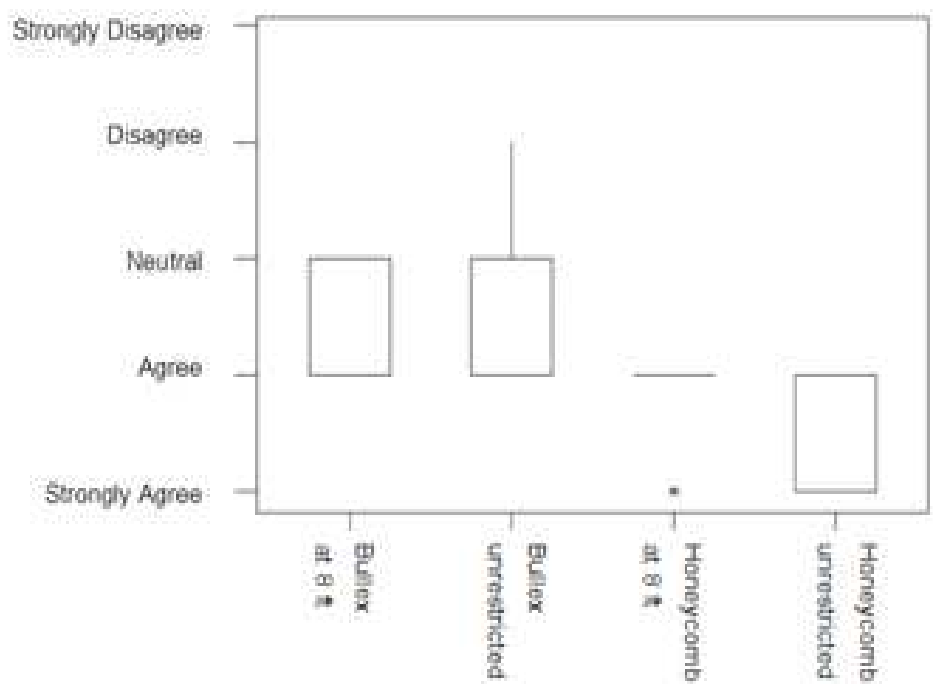

Fig. 7. Participant responses to "I recommend using this apparatus and method for training"

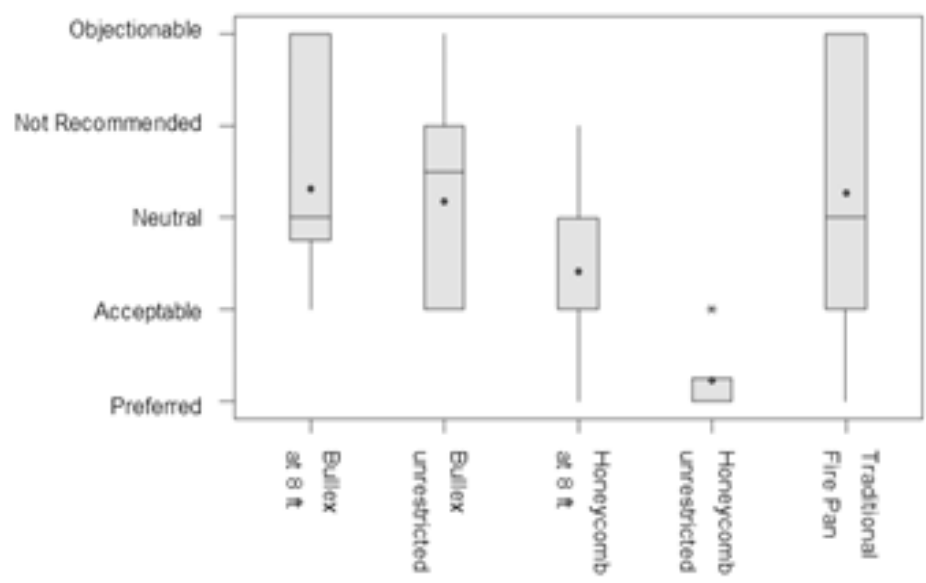

Fig. 8. Participant ratings for the five training methods 
All participants were able to use the training extinguisher for a minimum of four times; once for each of the study conditions. About two-thirds of the participants continued to experiment with the extinguishers and simulators after completing the study conditions. In general, participants accepted the training extinguisher with few concerns; although some thought it was lighter than they would normally expect, everyone operated it with normal ease. When asked to indicate the type of extinguisher that the training fire extinguisher most closely replicated, 13 participants $(59 \%)$ answered powder type, while the other 9 participants answered water.

All participants wrote comments and suggestions on their study form. The following is a list of selected comments that represent all what the participants wrote or said during and after the study:

- "It is too easy to put out the FS1 fire"

- "The training fire extinguisher seems lighter than normal"

- $\quad$ "The Honeycomb looks rugged, but I liked how its flames react"

- $\quad$ "I like how the Honeycomb flames push back and move from one end to the other"

- "The Honeycomb fire felt more like a real fire"

- $\quad$ I like how you can get close to the Honeycomb fire"

- "I like how you need to chase the Honeycomb flames to put it out"

- "Any hands-on training is better than nothing; at least one can discharge the extinguisher"

- "Consider adding smoke and sound of people panicking to increase realism, maybe a sound of a dog barking"

\section{Discussion}

The ultimate goal of fire extinguisher training is to enable trainees to react in a manner that would reduce the overall risk of loss of life, injury and/or property damage. Trainees should not only be able to operate a fire extinguisher, but also be able to make the right decision to fight or evacuate, choose the right extinguisher type and use it effectively. Therefore, fire extinguisher training aims to develop the trainees' skills, knowledge and understanding (safety skull cap "SKU"). Theoretical training such as classroom instructions, video and or computer-based instruction can effectively increase a trainee's knowledge and understanding. However, theoretical training does not develop skill; only through hands-on training skills can be developed and verified. Conversely, hands-on training is not the most efficient or effective way to address knowledge and/or understanding. Therefore, fire extinguisher training ideally should combine theoretical training with a hands-on component; both developers of the fire simulators used in this study adhere to this philosophy.

The participants of this study were considered experts in the use of fire extinguishers and all had the SKUs needed to use extinguishers effectively and remain unharmed. Before the beginning of the study, researchers made it clear to participants that they were to consider the use of a fire simulator for hands-on training to be a complementary method to theoretical training, not a replacement. As a result, their responses to the survey items should reflect what skills they deemed necessary for a trainee to learn and whether or not the studied hands-on training method could facilitate learning of such skills.

Based on informal discussions with the participants after they had completed the experiment and also from the written comments and suggestions provided, a list of skills to be addressed by hands-on training was identified. Skills identified include identifying type of extinguisher, operating extinguisher and discharging extinguishing agent, choosing safe and effective fighting distances, developing a feel for the total discharge time and gaining familiarity with the overall emergency environment so that a trainee can make the right decisions and perform correctly even under the stress of the situation. Although all of these skills can and should be addressed in the theoretical part of fire extinguisher training, only hands-on training allows the skills to be practiced, refined and verified.

Overwhelmingly, participants reported that putting out the honeycomb fire was more realistic than putting out the FS1. Although both simulators had real and equally sized flames, the flames on the FS1 unit were unrealistically easy to extinguish and did not react to extinguishment as real flames. This may be explained by how the FS1 operates; the extinguisher stream does not put out flames directly. Instead, sonic sensors on FS1detect direction and movement pattern of the extinguisher stream and then the flow of propane is controlled to reducing or killing the flames as per a computer program. Technically, it may be possible to alter the flame behavior in the FS1 by using different sensors and/or adjusting the control program, but another issue remains with the FS1 simulator. The design of the FS1 burner consists of holes in a pipe and each hole is unshielded. Thus, flames can be easily blown off these holes when participants get closer to the fire. In contrast, participants were only successful in putting out the honeycomb fire when they moved closer and subsequently chased the flame front by sweeping the discharge stream at the base of the fire and across the surface of the honeycomb panel.

During discussions, participants expressed a common theme: Better fire simulations lead to better training. 
This was also clear from the survey: The ratings associated with both the restricted training method and the FS1 simulator were lower than those associated with the unrestricted training method and the Honeycomb simulator. The ratings for the first statement ("Putting out this fire simulated putting out a real fire") fell primarily between "agree" and "strongly agree" for the Honeycomb simulator in both the restricted and unrestricted conditions (Fig. 4). The ratings suggest that the difficulty of extinguishment and reaction of the Honeycomb's flames were as expected by the participants and imply that the fire in the Honeycomb simulator behaved realistically. For example, as participants aimed the discharge stream at the base of the fire, the flame height dropped in front of the discharge stream. When participants conducted a sweeping motion with the discharge stream, a flame front was formed. Subjects then would need to continue this sweeping motion, chasing the flame front until the fire was completely out. The Honeycomb flames were difficult to put out from $2.44 \mathrm{~m}$ ( $8 \mathrm{ft}$.) away, just as participants apparently expected. In fact, 21 out of 22 participants failed to put out the Honeycomb flames in the restricted study condition. In contrast, when participants attempted to fight the FS1 fire from $2.44 \mathrm{~m}$ (8ft.) away, the flames did not react in any noticeable way to the extinguisher discharge stream. In this condition, participants were told to aim low and keep sweeping until the sensors registered the correct motion and shut off the gas flow. Additionally, although the FS1 system has settings to simulate an A, B, or C type fires (Bullex ITS, 2012), no difference in flame behavior could be detected by the researchers with either the naked eye or on video. Nor did the literature provided with the FS1 system provide any explanation/description of the differences between these settings. Only with the FS1 did participants disagree with the statement "putting out this fire simulated putting out a real fire." Based on the participants' responses, the FS1 did not realistically simulate the behavior of an actual fire; rather, participants perceived the Honeycomb simulator as considerably more realistic flame-behavior.

About one-third of the participants disagreed with the statement that using the FS1 at an 8-foot distance would help trainees safely put out an actual fire. On the other hand, none of the participants disagreed with this statement with respect to the honeycomb simulator. Further, on a five likert rating scale, the honeycomb simulator was rated a full two points better than the FS1 system. Once again, this may be due to both the FS1's unrealistic fire behavior and the requirement to stay 2.44 $\mathrm{m}$ (8ft.) away. Some participants expressed a concern that training with the FS1 simulator may give trainees a false sense of confidence as they felt it was unrealistically easy to put out the FS1 fire. Participants also indicated that training with the FS1 simulator created an artificial situation that deviates substantially from common knowledge and practices. They indicated that keeping at least $2.44 \mathrm{~m}(8 \mathrm{ft}$.) away conflicts with the need to get closer to a fire in order to extinguish it. Also, several participants mentioned that the effective fighting distance for a $\mathrm{CO}_{2}$ extinguisher is actually

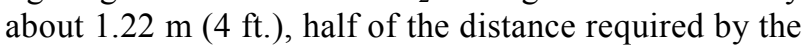
FS1. A person using the $\mathrm{CO}_{2}$ from $2.44 \mathrm{~m}$ ( $8 \mathrm{ft}$.) away will never be able to extinguish a fire. Finally, these concerns suggest that the conclusion in Poole's study (Poole, 2012) - most ordinary people should be able to extinguish a fire successfully without prior training may have been distorted somewhat by their use of the FS1 simulator in that study.

Although participants were critical in their assessment of the FS1 simulator, they did not dismiss it as a training device. Only few participants would not recommend using the FS1 simulator for training; most responses were neutral. Participants clearly valued any form of hands-on training over theoretical training alone. Several commented that the stress of the emergency situation, quickness of fire spread, small capacity of portable extinguishers and the very short discharge time leave no room for experimentation in an actual fire scenario. Therefore, concluding that there are no acceptable alternatives to hands-on training. Participants also added that, despite FS1 deficiencies, trainees still would gain valuable skills and experience using the FS1 simulator - including how to operate a fire extinguisher, discharging it and gaining a sense of the effort and time involved in using an extinguisher.

With respect to the five training methods (including the traditional fire pan), responses were consistent with the responses after each of the study conditions. The FS1 simulator received the most negative ratings, with the unrestricted condition receiving fewer objections and more recommendations than the restricted condition. However, the unrestricted condition with the FS1 is not viable outside the laboratory, as it violates the manufacturer's specifications for proper use (and can extinguish the unit's pilot light). Notably, the traditional fire pan method received the widest range of ratings. On one hand, some participants objected to it because of cost and the resulting mess. Others, however, gave better scores to the fire pan since it was closest to a real fire scenario, commenting that the actual smoke and fire associated with this method make it superior to any simulated fire. Along those lines, given that sound and lighting effects are commonly used in the training of professional firefighters to simulate emergency situations, it was not entirely surprising that several participants recommended improving realism through adding such effects to both simulators.

In regards to the extinguishing methods, no statistically significant differences were found between the restricted and unrestricted study conditions for each 
simulator. However, numerous comments highlighted that restricting the fighting distance to $2.44 \mathrm{~m} \mathrm{(8ft.)}$ could be problematic and confusing to trainees. In fact, several participants emphasized that the proper way to use a fire extinguishers requires one to start at a safe fighting distance 2.44 to $3 \mathrm{~m}$. ( 8 to $10 \mathrm{ft}$.) and then move closer to the fire source. Others expressed concern that a trainee may fail to put a fire in a real situation due to the perception he or she must keep a distance of $2.44 \mathrm{~m}(8$ $\mathrm{ft}$.) from the fire source.

Limitations of this study stem from the differences between experts who participated in this study and the average trainee. While the findings of this study gave insight to what is accepted and valued by experts, the ultimate verification would come from prospective trainees and how well they learn and retain the skills necessary to use a portable fire extinguisher. Given that the objective of fire extinguisher training is to enable a trainee to make the right decisions and perform correctly in a fire emergency situation, any subsequent further study of these training methods and apparatuses should involve trainees. If future studies confirm the findings by Poole (2012), then the differences identified between these fire simulators may be irrelevant for training purposes.

\section{Conclusion}

Hands-on fire extinguisher training is a vital component for developing and verifying critical firefighting skills. Controlled fires that are easy to ignite and reignite provide a suitable method for trainees to repeat the practice easily. The air pressurized water extinguishers used in this study are ideal for training, as they create little impact on the environment, moreover, are quickly and easily recharged.

The statistical analyses and the participant comments both indicate that realism in fire simulation is important. In order to ensure the best training outcomes, controlled fires should simulate fire behavior realistically and a trainee must practice the same actions they should use in an actual fire scenario. The Honeycomb and the FS1 simulators are both burn propane therefore, both have low environmental impact as.

FS1 appears to fall short in terms of accurately representing actual fire behavior during extinguishment. Furthermore, the method requires trainees to stay $2.44 \mathrm{~m}$ (8 ft.) away from the fire at all times, which is inconsistent with the practices recommended by the NFPA. On the other hand, the honeycomb simulator provided a more accurate fire simulation as the flames reacted normally to extinguishment and trainees were allowed to extinguish the fire from any distance. Most notably, all twenty-two of the expert fire extinguisher users who participated in this study preferred the Honeycomb simulator over both the traditional fire pan and the FS1 simulator.

\section{Author's Contributions}

Awwad Dababneh: Idea, design and prototype building of the "Honeycomb" fire simulator. Participated in the design of experiment, analyses, writing and revising the paper.

Abdul Jaleel Hamad Majeed and Rami H. Fouad: Participated in the Design of experiment, analyses, writing the revising the paper.

\section{Ethics}

Participants volunteered for the study and were not compensated for their time. There is no conflict of interests and results are published completely.

\section{References}

Blackburn, J.J., R. O'donnell and Thomas Rossi, 2010. Flameless fire extinguisher training methods and apparatus. United States Patent 7748983.

Bullex ITS, 2012. Provided by the manufacturer with new simulators. Bullex ITS User Reference Guide

Darois, P.R., S. Galonska, J. Blackburn, B.L. Swersey and T.B. Bashaw, 2007. Training device for extinguishing fires, method and system of use thereof. United States Patent 7175439.

Deshoux, T., J. Jaunasse and M. Seignard, 2000. Teaching installation for learning and practicing the use of fire-fighting equipment. United States Patent 6129552.

Hoglund, R.W., 2005. Firefighter's training simulator. United States Patent Application 233289.

HAI, 2010. Measuring the impact of fire extinguisher agents on cultural resource materials. Report prepared for the National Fire Protection Association-Fire Protection Research Foundation. Hughes Associates, Baltimore, MD.

Joynt, D.M., R.F. Debrody, E.M. Phillips, A.A. Zachmeier and D.C. Wright, 1995. Portable firefighter training system for fire extinguishing training. United States Patent 5447437.

Moore, W.T., 2004. Electronically simulated flame. United States Patent 6688752.

Quincy, M.A., 2007. Standard for portable fire extinguishers. National Fire Protection Association (NFPA).

OSHA, 2013. Fire protection, 1910.157, portable fire extinguishers. U.S. Department of Labor, Occupational Safety and Health Administration.

Poole, B., 2012. Ordinary people and effective operation of fire extinguishers. Unpublished dissertation, Eastern Kentucky University.

Williamson, S.J. and L. Orotelli, 2010. Dispersion burner for firefighter training. United States Patent 7744373. 